\title{
Joining the European Union leads to less cross-border collaboration
}

Brain drain from entering member states led to less-integrated research in countries of origin.

Daniel Cressey

12 April 2017

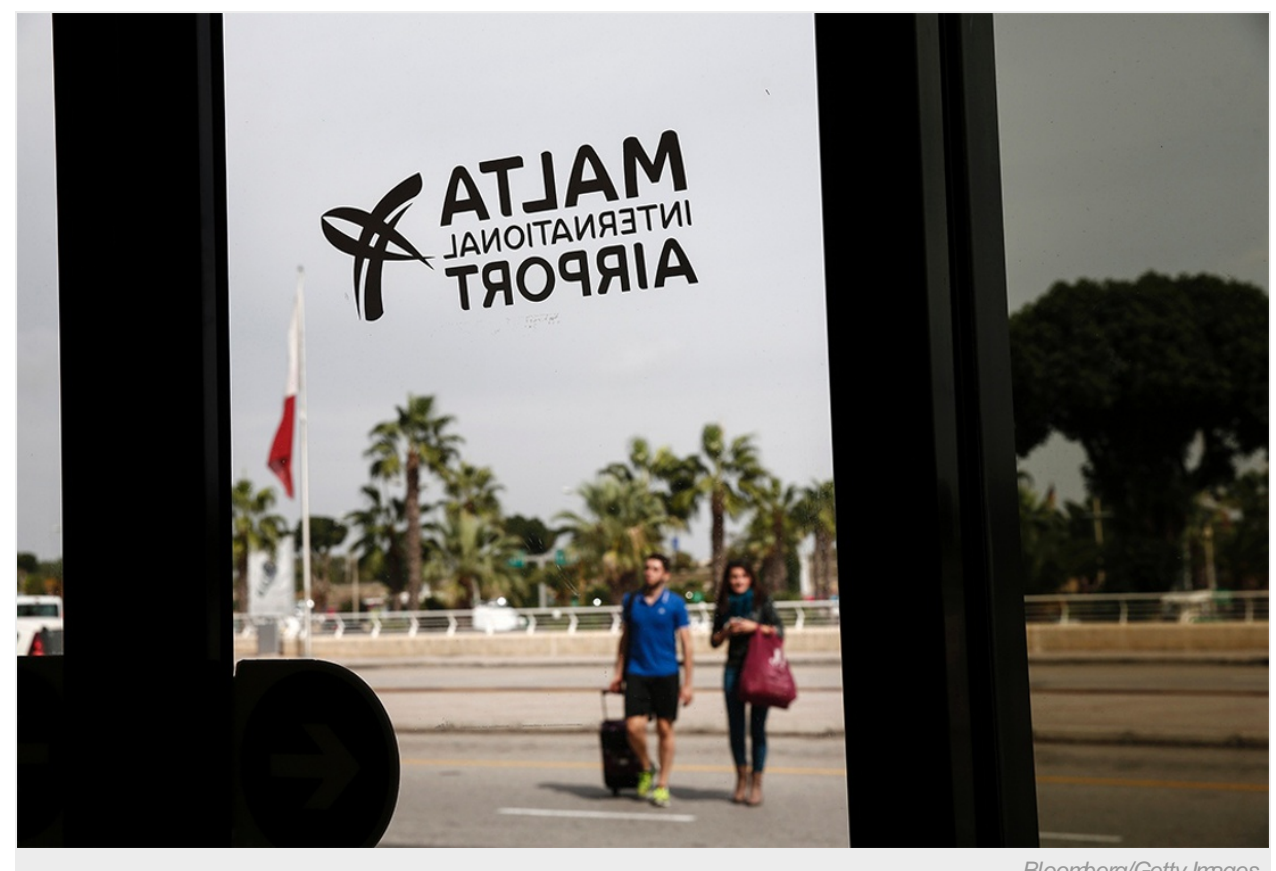

Bloomberg/Getty Images

Malta was among the ten countries that joined the European Union in 2004.

When the European Union expanded in the 2000s, it had a negative impact on scientific collaborations between researchers in new member countries and elsewhere, a study has found.

Membership in the EU gives countries access to the bloc's huge science-funding schemes and to the European Research Area (ERA), which strives for a border-free, well-funded, pan-European system of science. But according to a paper published on 12 April in Science Advances ${ }^{1}$, countries that joined in two waves of expansion - ten new members in 2004 and two more in 2007, all but three of them part of the former Soviet bloc - would have had more cross-border collaboration between scientists if they had not joined.

The findings "challenge central tenets underlying ERA integration policies," write the authors.

\section{Collaboration cuts}

In the paper, Alexander Petersen, a computational social scientist at the University of California, Merced, and his co-authors assess the collaboration rates of countries based on publication involving authors from more than one nation.

They found a much slower increase in Eastern European rates of collaboration per publication in the decade after 2004 than in previous ones (see Inter-EU brain drain). They also modelled what the cross-border publication rate might have been, had those 12 countries not joined the EU. According to the team's results, nations that joined in 2004 — such as Poland and Lithuania — saw $9 \%$ fewer cross-border publications than they might have expected given their scientific and economic metrics, such as spending on research and development. 
INTER-EU BRAIN DRAIN

The expansion of the European Union in 2004 and 2007 set back international collaboration in new member states.

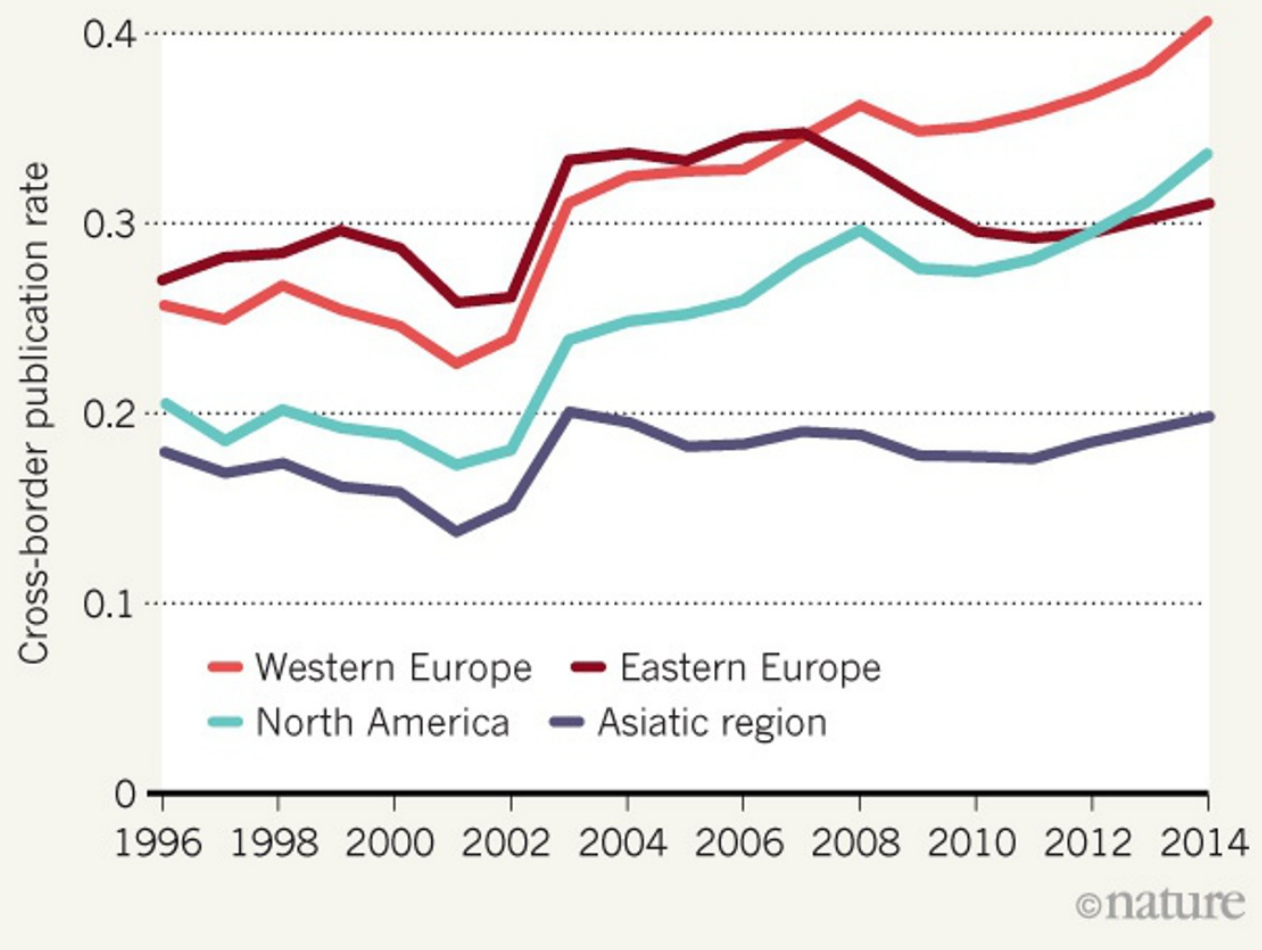

When countries join the EU, their citizens generally also gain the automatic right to work in any other EU member state, which raises the risk of a 'brain drain'. Petersen says that promising young academics who work in their home states often establish cross-border collaborations. But if those same researchers move west, their countries of origin lose not only their human capital, but also their bridges with the rest of the world. "And this process naturally explains what we found in our paper Eastern European countries would have been more integrated within science had they never integrated within the EU," he says.

Petersen thinks that the ERA is "great for multiple reasons", including that it brings together

countries with different innovation systems. He also says that the EU is doing a good job of dealing with the problems identified in this paper, for instance through programmes that pair Eastern-European institutions with Western ones. The latest paper shows, however, that Eastern European countries should invest in collaboration with Western countries, but should also implement 'home-return' conditions to make sure scientists come back at some point, he says.

\section{Brexit pressure}

The research comes at a crucial time for scientific collaboration in the EU, given that one of its major players — the United Kingdom — is about to leave the bloc. Several groups, including the League of European Research Universities (LERU) and the European University Association, called last month for "new momentum" to be given to the ERA, by setting more ambitious goals and expanding beyond Europe.

"Of course there has been brain drain," says Kurt Deketelaere, secretary-general of LERU and a professor of law at the University of Leuven in Belgium. But it did not have to happen, he says. Deketelaere faults the new member states for not strengthening their own research systems in line with the ERA aims.

"If they had done that, they would have experienced brain circulation, much less brain drain and have a much better-performing research system," he says.

Commenting on the paper, a European Commission spokesperson said in a statement, "In recent years, transnational cooperation between member states has grown by $7.8 \%$ - an encouraging sign that ERA is working. But it is now up to member states in particular to further improve the implementation of ERA."

The commission will assist with this by helping lower-performing countries improve their scientific efforts, the spokesperson added.

Nature I doi:10.1038/nature.2017.21825

\section{References}

1. Doria Arrieta, O. A., Pammolli, F. \& Petersen, A. M. Sci. Adv. 3, e1602232 (2017). 